\title{
Proposing a rigorous empirical model for estimating the bubble point pressure in heterogeneous carbonate reservoirs
}

\author{
Alireza Rostami ${ }^{1 \oplus *}$, Alireza Daneshi², Rohaldin Miri ${ }^{3}$ \\ ${ }^{1}$ Department of Petroleum Engineering, Petroleum University of Technology (PUT), Ahwaz, Iran \\ ${ }^{2}$ Oil and Gas Fields and Equipment Research and Development Center, Shahid Chamran University, Ahwaz, Iran \\ ${ }^{3}$ Department of Petroleum Engineering, Iran University of Science and Technology (IUST), Tehran, Iran
}

Keywords:

Bubble point pressure

gene expression programming

correlation

sensitivity analysis

comprehensive error analysis

Cited as:

Rostami, A., Daneshi, A., Miri, R. Proposing a rigorous empirical model for estimating the bubble point pressure in heterogeneous carbonate reservoirs. Advances in Geo-Energy Research, 2020, 4(2): 126-134, doi:

10.26804/ager.2020.02.02.

\begin{abstract}
:
Bubble point pressure is of great significance in reservoir engineering calculations affecting the success of reservoir simulation. For determining this valuable parameter, experimental tests are the most reliable techniques; however, these measurements are costly and timeconsuming. So, it is crucial to propose an empirical model for estimating bubble point pressure. The existing correlations mainly have large errors and develop based on restricted database from a specific geographical location. As a result, development of an all-inclusive correlation is essential. In current article, gene expression programming (GEP) was used to create a generalized model for bubble point pressure estimation. To do this, an allinclusive source of data was utilized for training and testing the model from the petroleum industry. Several statistical approaches including both illustration tools and diverse error functions were utilized to show the supremacy of the developed GEP model. Consequently, the recommended model is the most accurate as compared to the similar correlations in literature with the average absolute relative error $(\mathrm{AARE}=11.41 \%)$ and determination coefficient $\left(\mathrm{R}^{2}=0.96\right)$. Furthermore, the solution gas-oil ratio shows to be the most influencing variable on determining bubble point pressure according to sensitivity analysis. The results of contour map analysis demonstrate that most portions of the experimental region are predicted via the GEP equation with fewer errors as compared to two well-known literature correlations. Finally, the proposed GEP model can be of high prominence for accurate bubble point pressure estimation.
\end{abstract}

\section{Introduction}

A sufficient understanding of any pressure-volumetemperature (PVT) characteristic is vital in computations of reservoir engineering including formation evaluation, material balance calculations, inflow performance calculations, reserve estimation, fluid flow in porous media, well test analysis, planning upcoming enhanced oil recovery processes, production equipment design, and numerical reservoir simulations (Petrosky Jr and Farshad, 1993; Khoukhi et al., 2010; Ikiensikimama et al., 2012). Properties of the reservoir fluid, for instance, bubble point pressure, are of principal prominence for calculating production capacity, recoverable reserve, and closely all other features of petroleum engineering computations (Vazquez and Beggs, 1977; Ostermann and Owolabi,
1983; Petrosky Jr and Farshad, 1993; Bandyopadhyay et al., 2011). Therefore, proper determination of bubble point pressure is crucial in PVT analyses.

There are several approaches for determining bubble point pressure including experimental measurement, theoretical modeling, and empirical techniques. Experimentation is expensive and time-demanding. Mathematical and theoretical models are also complex and not easy to use. Besides, these models use simplifying assumptions that introduce some errors in the estimations. So, the application of the empirical correlations is of great significance for the engineers. Because they prepare a cheap and quick estimate of the output easily.

There is an extensive background of the empirical models in the literature concerning the bubble point pressure prediction (Lasater, 1958; Standing, 1977; Vazquez and Beggs, 1977;

${ }^{*}$ Corresponding author.

E-mail address: alireza.rostami.put2014@gmail.com, alireza.rostami@afp.put.ac.ir \& rostami.a@nisoc.ir (A. Rostami);

Daneshi580@gmail.com (A. Daneshi); rohaldinmiri@iust.ac.ir (R. Miri). 2207-9963 (C) The Author(s) 2020.

Received February 27, 2020; revised March 18, 2020; accepted March 26, 2020; available online April 1, 2020. 
Glaso, 1980; Al-Marhoun, 1988; Petrosky Jr and Farshad, 1993; McCain et al., 1998). Standing (1947) is the pioneer of PVT studies in petroleum engineering. In his work, three PVT correlations were presented for California crude oil, although they were checked for crude oils from other geographical locations. For ease of use, calculation charts have been prepared for each of their correlations. In 1958, Lasater (1958) used the 158 data obtained from South America, the United States, and Canada to create a bubble point pressure model. In another study, Petrosky Jr and Farshad (1993) established several empirical correlations for the Gulf of Mexico including bubble point pressure, solution gas-oil ratio, undersaturated isothermal oil compressibility, and oil formation volume factor at bubble point. Their models have strong functionality with the available field data. McCain et al. (1998) conducted three strategies including neural network analysis, classical regression, and non-parametric regression to develop three bubble point pressure models. Both traditional regression and nonparametric regression had the same accuracy, and the neural network model led to the least error. This is the first time that neural network tool was applied in PVT calculations or even in petroleum engineering. Recently, Moradi et al. (2010) have conducted a thorough literature review on the whole published correlations. Then, they developed a new equation for estimating bubble point pressure in terms of temperature, solution gas-oil ratio, gas and stock tank specific gravities as input for modeling via multiple regression analysis. Finally, they found that their model is the best-acting one based on their collected database with a total error of less than $17 \%$. In addition to the abovementioned empirical models proposed for bubble point estimation, several artificial intelligence methods have been published in the literature (Ahmadi et al., 2015; Alakbari et al., 2016; Elkatatny et al., 2018). Rafiee-Taghanaki et al. (2013) have developed a hybrid model based on support vector machine to predict PVT properties of the crude oil such as saturation pressure. Finally, by a comparative study, the authors concluded that their model is the most accurate one. Asoodeh and Bagheripour (2012) firstly developed some neural network, fuzzy logic and their combined models for bubble point prediction. Then, a power-law based model was developed using pattern search-genetic algorithm. The comparison of the developed models with experimental data illustrates the good agreement of the suggested techniques in this study. In 2015, a committee based model namely, committee machine intelligent system (CMIS) was created by Shokrollahi et al. (2015) to predict oil formation volume factor and bubble point pressure. The results of diverse error functions showed the high capability of the developed CMIS model for PVT calculations. Talebi et al. (2014) developed a strong version of neural network models named as, radial basis function neural network (RBFNN), to predict saturation pressure of the crude oil. The results of statistical analysis prove the superiority of the RBFNN model over the empirical models.

These smart techniques are black-box approaches that do not prepare a perceptible physical model for petroleum engineers in their future studies. The established literature correlations are mainly extended based on the specific range of datasets. They are not general models and their application to out range leads to considerable errors. Consequently, there is a great demand for the development of general and somehow predictive models covering a wide operational range (Rostami et al., 2019).

Soft computation is one of the most promising approaches for creating sufficiently accurate models in wide disciplines of engineering and science (Kamari et al., 2017). Amongst these approaches, gene expression programming (GEP) is the most recently established approach applied for establishing general correlations. There is diverse usage of GEP strategy in the literature demonstrating the large strength of such techniques in chemical and petroleum engineering. The main advantage of the pre-mentioned method is that it does not need to assume a certain regression model type before running the model. The suitable empirical model will be suggested by the GEP approach with no preliminary assumption (Rostami et al., 2019).

In this work, the main objective is to put forward a proper empirical model for determining bubble point pressure. At first, a large dataset was prepared based on the 93 bubble point data obtained from the southern oilfields of the Iranian reservoir. Using the GEP strategy, a universal model was developed for the first time, and then, the model predictions were compared with some common published models in the literature. Many graphics and statistical parameters are used to evaluate the accuracy and trustfulness of the suggested model here. Sensitivity analysis was also carried out to show each variable impact value on the model prediction capacity.

\section{Methodology}

The classical version of genetic programming (GP) has been improved by introducing its new version named as, gene expression programming (GEP), which was developed through the work of Ferreira (Ferreira, 2006; Rostami et al., 2019). This class of mathematical approach has two main constituents including chromosome and expression tree. The candidate or primary solutions are indicated by chromosomes. By a translation process, chromosomes will be translated to expression trees leading to the generation of more powerful solutions (Ferreira, 2006; Rostami et al., 2019). The GEP technique is inspired by the natural translation process of DNAs to chromosomes. Fig. 1 illustrates a typical GEP structure with two genes. In GEP modeling, a fitness function for example root mean square error (RMSE) will be set. When the convergence criterion is satisfied, the GEP processing will be concluded (Ferreira, 2006; Rostami et al., 2019). The main procedure for model development is described as follows (Ferreira, 2006; Rostami et al., 2019):

1) First step is known as population initialization, in which chromosomes with specific individuals will be set randomly leading to the express of different correlations.

2) Based on the fitness function (here, RMSE), the fitting process onto the population individuals will be done.

3) Based on the calculated fitness function, new population individuals will be chosen to modify the answer.

4) Via applying some methods such as selected environment 
Table 1. Description of the applied database used for modeling.

\begin{tabular}{llllll}
\hline Parameter & Unit & Min. & Avg. & Max. & STDEV \\
\hline$T$ & ${ }^{\circ} \mathrm{F}$ & 100 & 183.62 & 288.5 & 57.92 \\
$R_{S}$ & SCF/STB & 105.58 & 728.47 & 2729 & 517.85 \\
$\gamma_{S T O}$ & Unitless & 0.82 & 0.89 & 0.95 & 0.03 \\
$\gamma_{g}$ & Unitless & 0.66 & 1.06 & 1.74 & 0.16 \\
$P_{b}$ & psi & 287 & 2206.41 & 5491 & 1152.11 \\
\hline
\end{tabular}

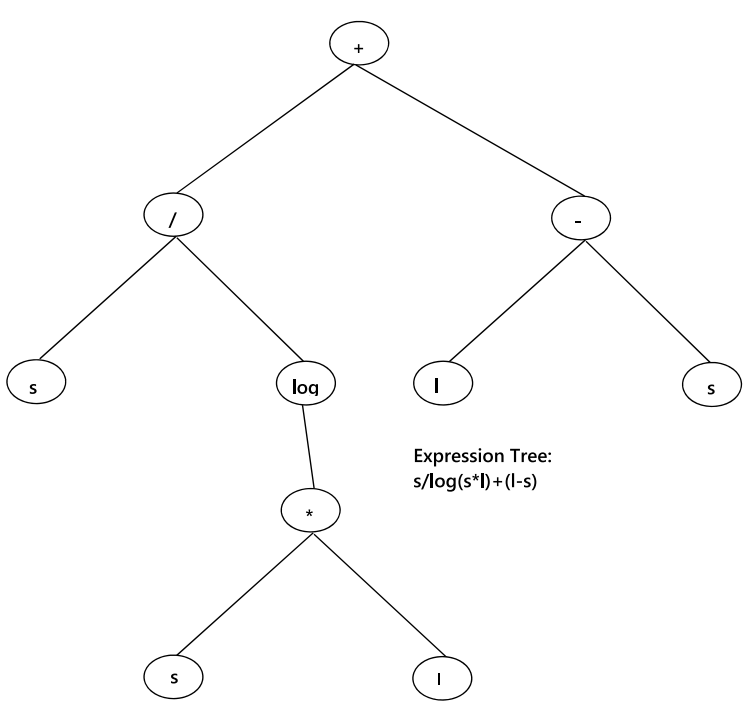

Fig. 1. A typical structure of a two-gene GEP algorithm.

confrontation, selection, expression of the genomes, and reproduction with modification, new population individuals are behaved properly.

5) The standard criterion will be reached via repeating the above steps.

\section{Data mining}

As known, the development of an extensive and reliable model is in the need of the database comprehensiveness (Rostami et al., 2019). Therefore, in this study, 93 bubble point pressure data in association with the other PVT properties including temperature, solution gas-oil ratio, API gravity of the residual oil in stock tank liquid, and the total gas specific gravity of the evolved gas, were undertaken from the petroleum industry. After that, the dataset was separated into the two groups of testing for checking the estimation capacity and training to create the main model. Table 1 shows the statistical ranges of the applied database for modeling. As this table shows, the range of operational parameters is sufficiently wide in which it can be employed for model development. It is worthwhile mentioning that 19 and 74 data points were allocated to testing and training phases, respectively. Fig. 2 shows the variation of bubble point pressure in terms of different input variables via contour map analysis. As can be seen, decreasing specific gas and oil gravities will lead to increasing bubble point pressure; however, for solution gas-oil ratios more than $1400 \mathrm{SCF} / \mathrm{STB}$ and temperatures greater than $230{ }^{\circ} \mathrm{F}$, bubble point pressure will be more than 3000 psi.

\section{Results and discussion}

In this section, the GEP mathematical algorithm was employed for estimating bubble point pressure as a function of some well-known PVT parameters. Based on the bulk of literature focusing reservoir studies, bubble point pressure is a strong function of the solution gas-oil ratio, the specific gravity of residual oil in the stock tank, gas specific gravity and temperature (Standing, 1977; Al-Marhoun, 1988; Petrosky Jr and Farshad, 1993; McCain et al., 1998; Moradi et al., 2010; Ikiensikimama et al., 2012; Rafiee-Taghanaki et al., 2013; Shokrollahi et al., 2015; Alakbari et al., 2016). This functionality can be shown by the following formulation:

$$
P_{b}=f\left(R_{S}, \gamma_{S T O}, \gamma_{g}, T\right)
$$

where $R_{S}, \gamma_{S T O}, \gamma_{g}, T$ and $P_{b}$ stand for solution gas-oil ratio, the specific gravity of residual oil in the stock tank, gas specific gravity, temperature and bubble point pressure, respectively. The above-mentioned relationship helped the researchers to find a proper symbolic model for bubble point pressure estimation. In current investigation, the advanced mathematical modeling of GEP was proposed to estimate the bubble point pressure.

Then, it was evaluated by computing numerous statistical quality parameters such as average relative error (ARE), root mean square error (RMSE), determination coefficient $\left(\mathrm{R}^{2}\right)$, standard deviation (STDEV) and average absolute relative error (AARE). Some graphics were also utilized to prove the high capability of the model proposed in this study as compared to other correlations published in literature. The developed GEP model for estimating bubble point pressure is as follows:

$$
\begin{gathered}
P_{b}=A+B+C \\
A=\left(\frac{R_{S}}{\gamma_{g}}+R_{S}+4.113454 T+807.176902\right) \times \gamma_{S T O}^{\frac{1}{4}} \\
B=147.553638 \times \frac{10.252523+\gamma_{g}}{\gamma_{g}} \times \frac{0.428004 R_{S}-137.301116}{R_{S}} \\
C=-\left(1.568365 \frac{R_{S}}{T}+28.411213\right) \times \gamma_{g}^{2} \times R_{S}^{\frac{1}{2}}
\end{gathered}
$$




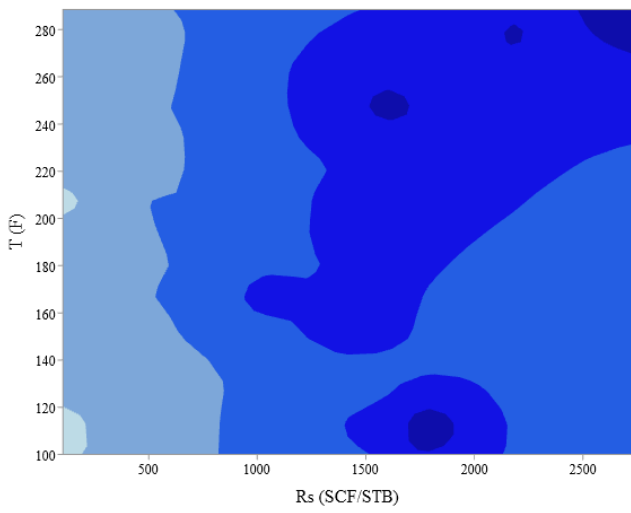

(a)

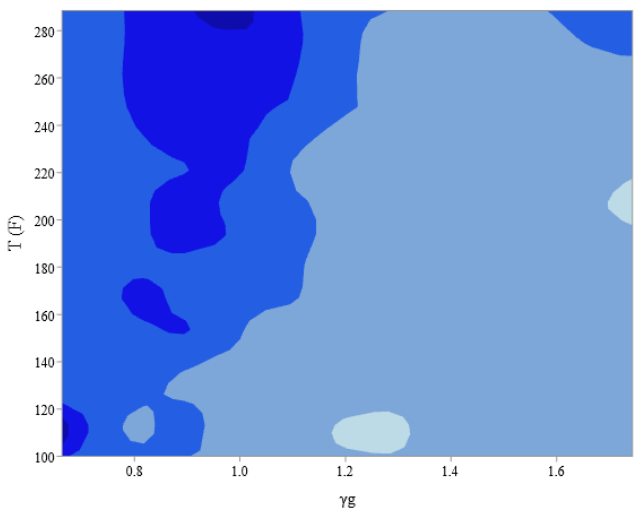

(c)

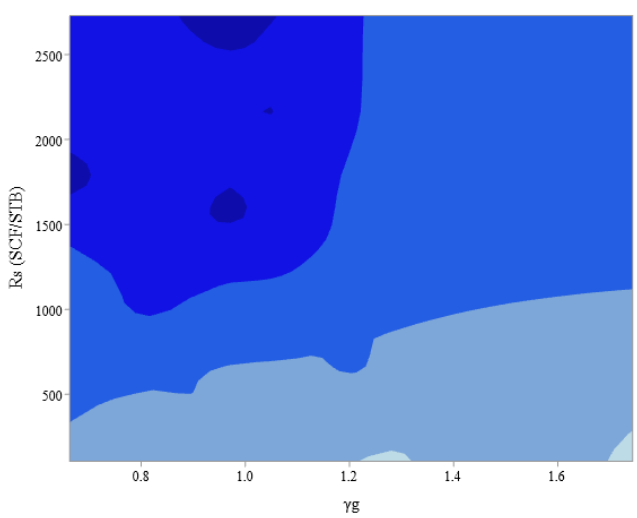

(e)
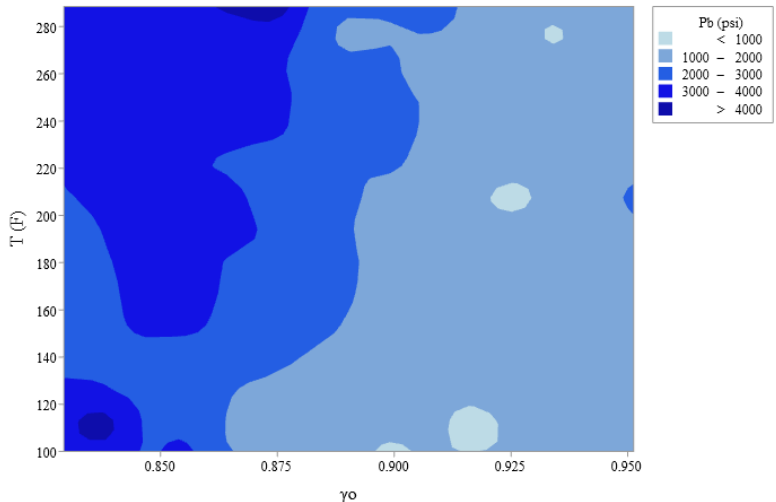

(b)

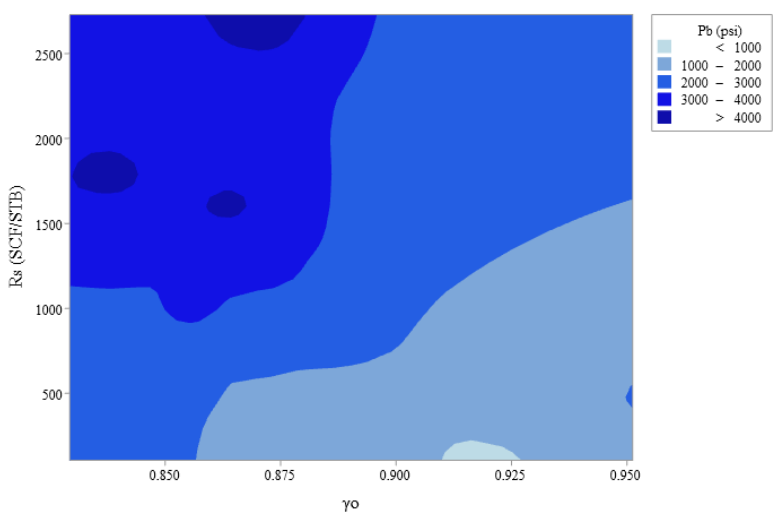

(d)

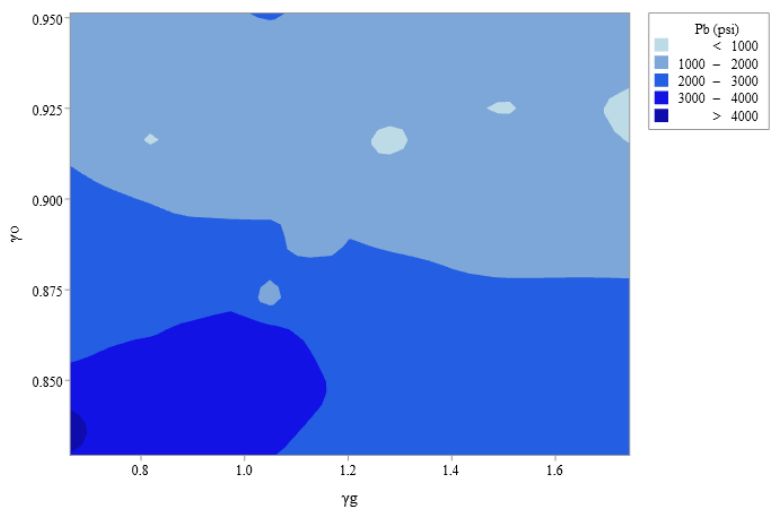

(f)

Fig. 2. Database variation with respect to different variables: (a) $P_{b}$ vs. $T$ and $R_{S}$, (b) $P_{b}$ vs. $T$ and $\gamma_{S T O}$; (c) $P_{b}$ vs. $T$ and $\gamma_{g}$; (d) $P_{b}$ vs. $R_{S}$ and $\gamma_{S T O}$; (e) $P_{b}$ vs. $R_{S}$ and $\gamma_{g}$; (f) $P_{b}$ vs. $\gamma_{S T O}$ and $\gamma_{g}$.

where the parameters of bubble point pressure (in psi), solution gas-oil ratio (in SCF/STB), the specific gravity of residual oil in the stock tank (dimensionless), gas specific gravity (unitless) and temperature $\left({ }^{\circ} \mathrm{F}\right)$, are symbolized with $P_{b}, R_{S}, \gamma_{S T O}$, and $\gamma_{g}$, respectively. Table 2 indicates the results of several error functions for various datasets including training, testing, and total. As can be seen from this table, for the total set, $\mathrm{R}^{2}$ and AARE values are equal to 0.96 and $11.41 \%$, respectively. The results of the test and train sets show that the GEP model has a reasonably good precision in estimating bubble point pressure. A parity diagram of the suggested GEP model in this study is illustrated in Fig. 3. This cross plot shows a fairly compressed accumulation of the database in the neighborhood of the $45^{\circ}$ line, which means that the GEP model has a good fitness to the experimental bubble point pressure. Both train and test sets are closely located nearby the unit slope line. The $\mathrm{R}^{2}$ values are equal to 0.96 and 0.98 for train and test sets, respectively, revealing high fitness of both pre-mentioned sets to measured data points.

The relative error distribution versus measured bubble point pressure is sketched in Fig. 4. As this figure shows, the relative error mainly varies from $-13 \%$ to $+14 \%$. Moreover, the data 
Table 2. Statistical quality measures of the developed GEP model in this study.

\begin{tabular}{|c|c|c|c|c|}
\hline Error function & Formula & Training set & Test set & Total set \\
\hline $\mathrm{R}^{2}$ & $\frac{\left(\sum_{i=1}^{N}\left(P_{b i}^{\text {exp }}-\overline{P_{b i}^{\text {exp }}}\right)\left(P_{b i}^{\text {pred }}-\overline{P_{b i}^{\text {pred }}}\right)\right)^{2}}{\sum_{i=1}^{N}\left(P_{b i}^{\exp }-\overline{P_{b i}^{\exp }}\right)^{2} \sum_{i=1}^{N}\left(P_{b i}^{\text {pred }} \overline{P_{b i}^{\text {pred }}}\right)^{2}}$ & 0.9595 & 0.9836 & 0.9638 \\
\hline ARE $(\%)$ & $\frac{100}{N} \sum_{i=1}^{N}\left(\frac{P_{b i}^{\exp }-P_{b i}^{\text {pred }}}{P_{b i}^{\exp }}\right)$ & -1.8725 & 11.8608 & 0.9333 \\
\hline AARE (\%) & $\frac{100}{N} \sum_{i=1}^{N}\left|\frac{P_{b i}^{\exp }-P_{b i}^{\text {pred }}}{P_{b i}^{\text {exp }}}\right|$ & 9.6494 & 18.2489 & 11.4063 \\
\hline RMSE & $\left(\frac{\sum_{i=1}^{N}\left(P_{b i}^{\exp }-P_{b i}^{\text {pred }}\right)^{2}}{N}\right)^{\frac{1}{2}}$ & 226.3366 & 185.0485 & 218.5364 \\
\hline STDEV & $\left\{\frac{1}{N-1} \sum_{i=1}^{N}\left(\frac{P_{b i}^{\exp }-P_{b i}^{\text {pred }}}{P_{b i}^{\exp }}\right)^{2}\right\}^{\frac{1}{2}}$ & 0.1492 & 0.4469 & 0.2419 \\
\hline $\mathrm{N}$ & & 74 & 19 & 93 \\
\hline
\end{tabular}

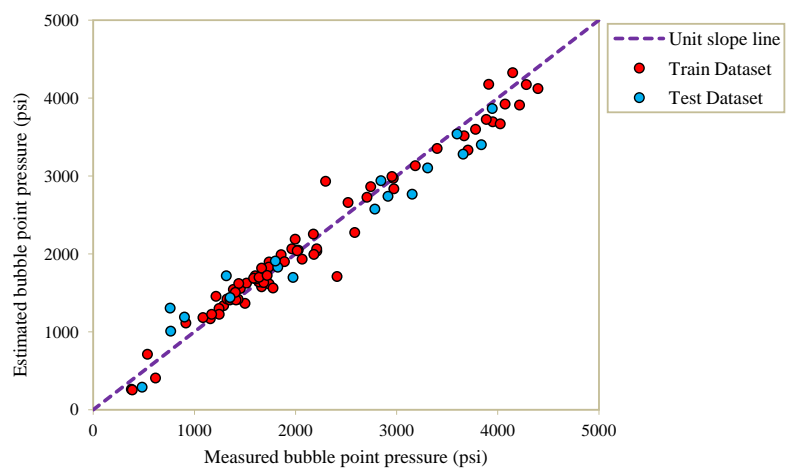

Fig. 3. Estimated bubble point pressure by the new GEP-based model here versus the measured bubble point pressure through cross plot representation.

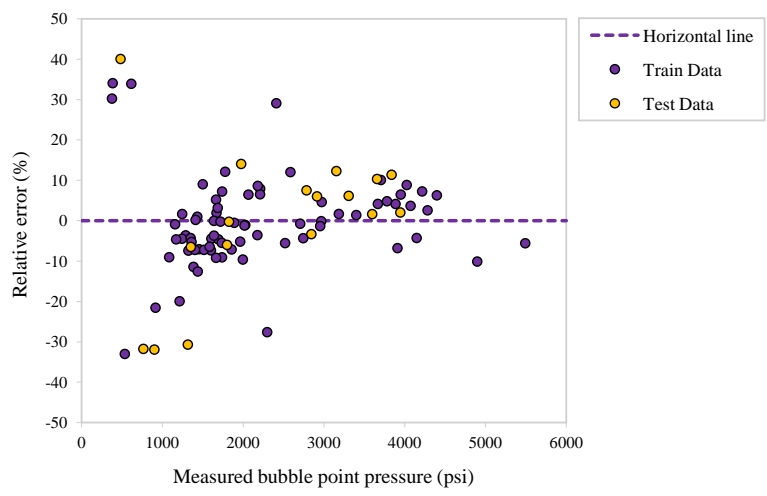

Fig. 4. Relative error distribution of the developed model for estimating bubble point pressure by new method against the measured data.

cloud is reasonably close to zero horizontal line. Moreover, for bubble point pressures ranging from 500 to $2300 \mathrm{psi}$, the error reaches to a maximum value. The other characteristic plot is indicated in Fig. 5 which shows the GEP estimates and the actual data versus the data index. Based on this diagram,

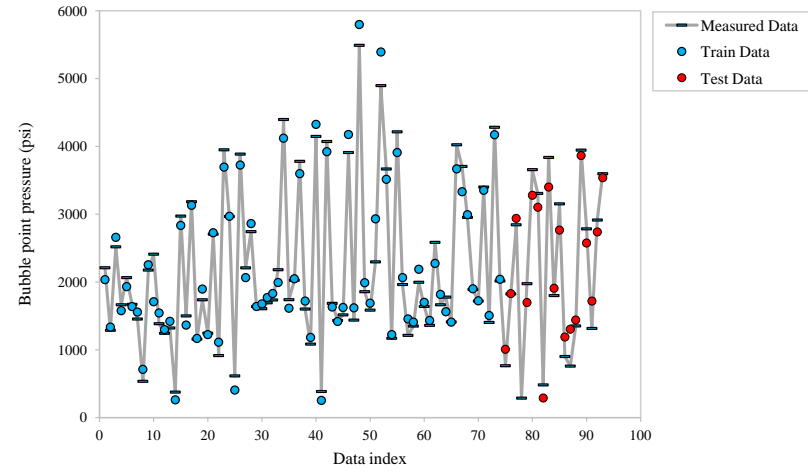

Fig. 5. Comparison of the estimated bubble point pressure with the experimental data.

there is a satisfactory agreement between both GEP estimates and the actual data. Obviously, for both train and test subsets, the trend of bubble point variation is properly detected by the GEP, because the peaks or ups and downs of bubble point pressure are precisely picked by the proposed GEP model. There is a good fitness in test subset between the measured data points and GEP estimates which shows the high capability of the developed model.

The next analysis is indicated in Fig. 6 which is wellknown as the sensitivity test. This analysis is conducted by using Pearson's technique with the following formula (Chok, 2010):

$$
r=\frac{\sum_{i=1}^{n}\left(I_{k, i}-\overline{I_{k}}\right)\left(O_{i}-\bar{O}\right)}{\sqrt{\sum_{i=1}^{n}\left(I_{k, i}-\overline{I_{k}}\right)^{2} \sum_{i=1}^{n}\left(O_{i}-\bar{O}\right)^{2}}}
$$

where $I_{k, i}, n, O_{i}, \bar{O}$ and $I_{k}$ represent $\mathrm{i}$-th input value of the $k$-th input parameter, the number of the dataset, $i$-th output value, mean value for output parameter and, mean value for the $k$-th input respectively. The normalized relevancy factors are reported in this study. In the pre-mentioned analysis, the 


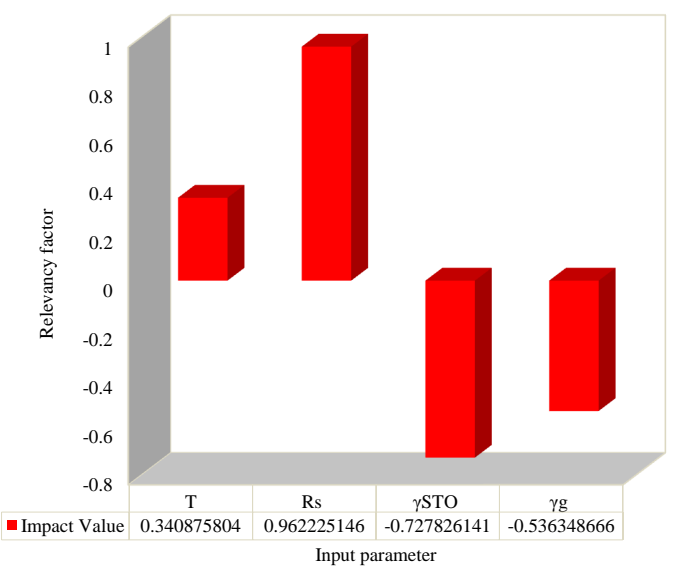

Fig. 6. Sensitivity analysis of the developed model for predicting bubble point pressure as a function of different input variables it shows that the suggested model is most sensitive to the solution-gas-oil ratio.

effect of each variable is determined by assigning a correlation coefficient ranging from -1 to +1 to the corresponding input variable. Positive and negative relevancy factors show increasing and decreasing trends of that variable, respectively (Chok, 2010). As shown here, temperature and solution gas-oil ratio have positive influence, and a decreasing trend can be observed by the variation of both specific gravity of the residual oil in the stock tank and specific gravity of the evolved gas. Moreover, the largest impact value is assigned to the solution gas-oil ratio. To assess the precision of the GEP model here, it is compared to two commonly applied literature correlations (i.e., Standing (1977) developed by 105 data and Al-Marhoun (1988) based on 160 data). Standing (1977) correlation (i.e., Eqs. (7) and (8)) and Al-Marhoun (1988) (i.e., Eq. (9)) are presented as below:

$$
\begin{gathered}
C N_{P_{b}}=\left(\frac{R_{S}}{\gamma_{g}}\right)^{0.83} \times 10^{(0.00091 \times T-0.0125 \times A P I)} \\
P_{b}=18.2 \times\left(C N_{P_{b}}-1.4\right) \\
P_{b}=5.38088 \times 10^{-3} \times R_{s}^{0.715082} \times \gamma_{g}^{-1.877840} \times \gamma_{S T O}^{3.143700} \\
\times(T+460)^{1.326570}
\end{gathered}
$$

In above equations, the parameters of bubble point pressure (in psi), solution gas-oil ratio (in SCF/STB), the specific gravity of residual oil in the stock tank (dimensionless), gas specific gravity (unitless) and temperature $\left({ }^{\circ} \mathrm{F}\right)$, are symbolized with $P_{b}, R_{S}, \gamma_{S T O}, \gamma_{g}$ and $T$, respectively.

Table 3 indicates comparisonal analysis of the GEP model with Standing (1977) and Al-Marhoun (1988) using wellknown statistical parameters. As shown, statistical error calculation represents that GEP, Standing (1977) and Al-Marhoun (1988) have the AARE values of $11.4 \%, 21.9 \%$, and $13.3 \%$, respectively. Moreover, assessing other parameters such as AARE, ARE and $\mathrm{R}^{2}$ demonstrates that the suggested GEP model is the most accurate technique. The Standing correlation gives the least accurate estimation of bubble point pressure
Table 3. Comparisonal analysis of the developed GEP model here with the two commonly published literature correlations.

\begin{tabular}{llll}
\hline Error function & GEP & Standing & Al-Marhoun \\
\hline $\mathrm{R}^{2}$ & 0.9638 & 0.9043 & 0.9400083 \\
ARE & 0.9333 & -21.3132 & 7.6200712 \\
AARE & 11.4063 & 21.8624 & 13.292958 \\
RMSE & 218.5364 & 751.4190 & 353.64798 \\
\hline Standing refers to (Standing, 1977); Al-Marhoun refers to (Al-Marhoun, 1988).
\end{tabular}

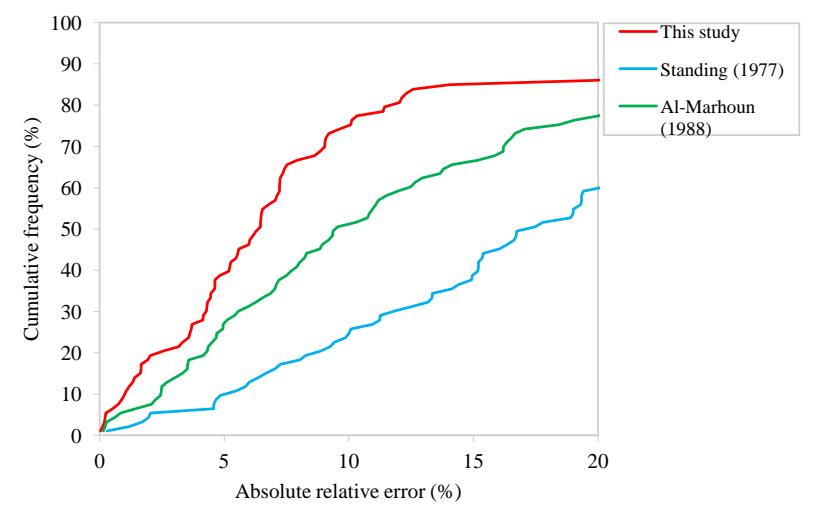

Fig. 7. Analysis of the cumulative frequency versus the absolute relative error percent for the developed model here predicting bubble point pressure - it shows that the larger portions of the estimates of this study has less errors as compared to other models.

due to its high AARE value. An additional tool for comparison is known as cumulative frequency analysis in terms of absolute relative error percent, which is represented in Fig. 7. According to this figure, about $86 \%$ of GEP model predictions, $60 \%$ of Standing (1977) estimates, and $77 \%$ of Al-Marhoun (1988) forecast, have absolute relative error percents equal or less than $20 \%$. In other words, the following order for the cumulative frequency of the absolute estimation error can be seen according to Fig. 7:

Current Study > Al-Marhoun (1988) > Standing (1977).

Fig. 8 indicates the error analysis for the GEP model and the studied correlations here. For this, contour map analysis applied to show the variation of absolute relative deviation (ARD) against the solution gas-oil ration and reservoir temperature. As can be seen, most portions of the contour map region shown for the GEP model is covered by blue and dark blue color, which leads to estimation errors less than 10\% (See Fig. 8(a)). For Standing (1977) and Al-Marhoun (1988), the main parts of operational conditions are covered, respectively, by estimation errors of more than $15 \%$, and 5$15 \%$. So the GEP model established here is the most accurate model and Standing (1977) correlation is the least one. Based on the drawn contour maps, the reservoir engineers can decide whether to apply the studied model or not in their engineering calculations. For example, Standing (1977) correlation gives ARD values more than $20 \%$ for temperatures more than 230 F (See Fig. 8(b)). The last analysis conducted here is the 


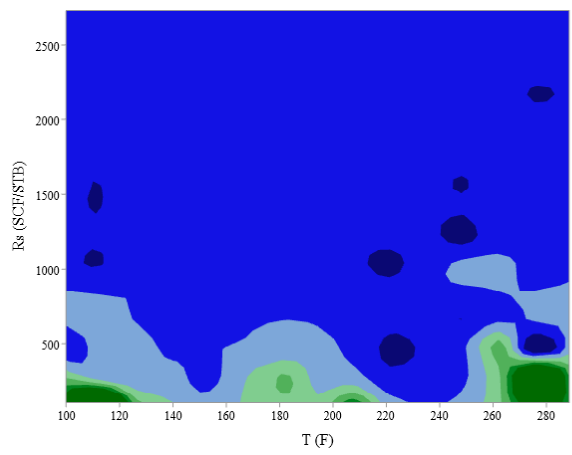

(a)
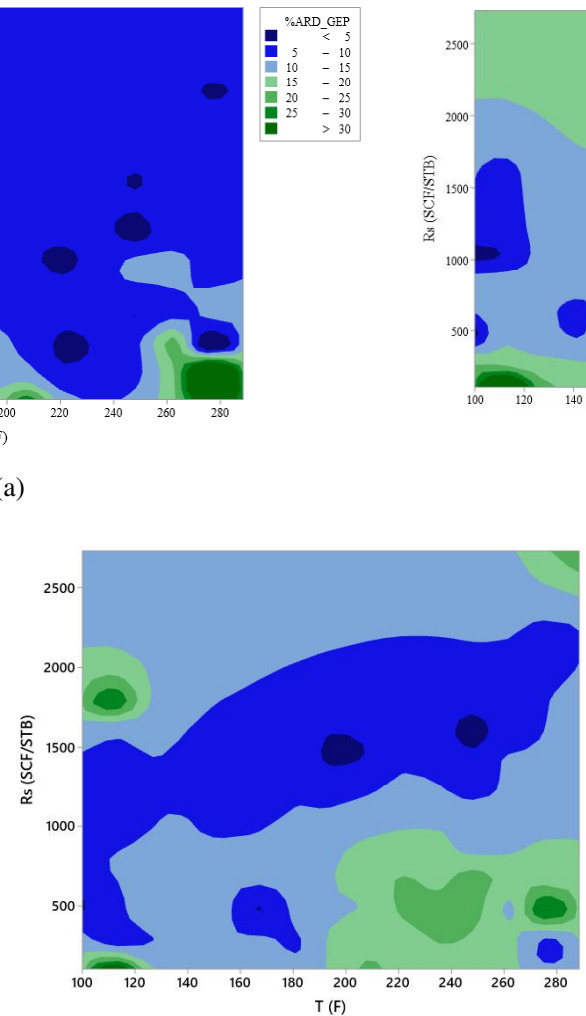

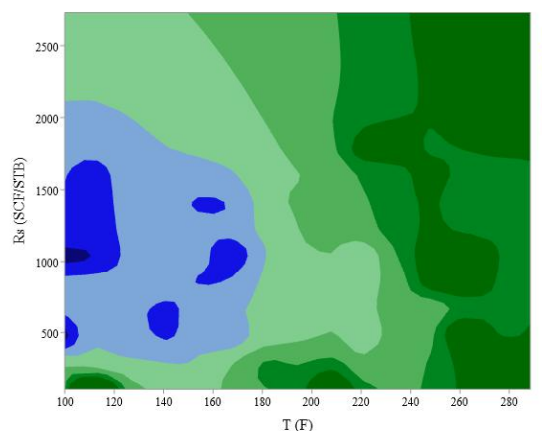

(b)

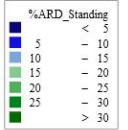

(c)

Fig. 8. Contour map analysis of the absolute relative deviation percent (\%ARD) for the proposed GEP model in this study as compared to two commonly used published correlations: (a) GEP; (b) Standing; (c) Al-Marhoun.

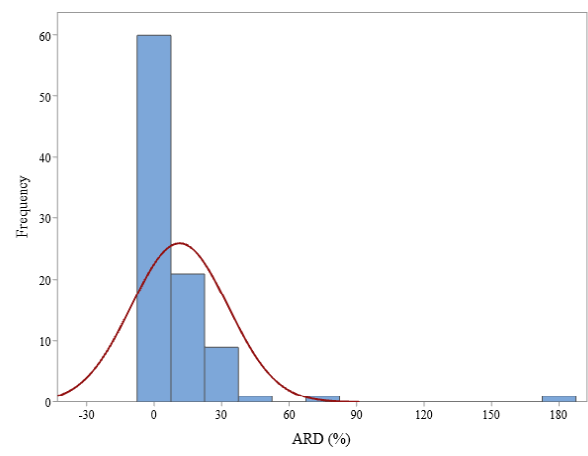

(a)

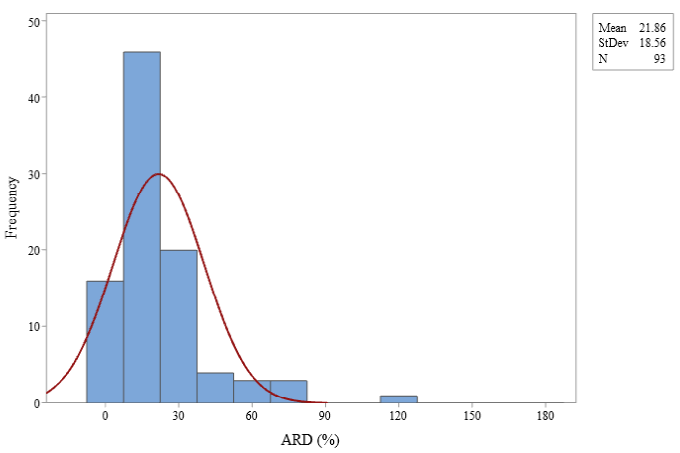

(b)

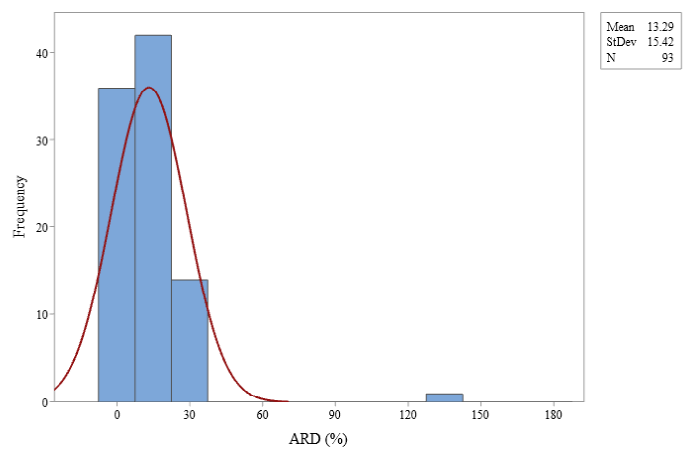

(c)

Fig. 9. Histogram analysis of the absolute relative deviation percent (ARD\%) for different models: (a) GEP; (b) Standing; (c) Al-Marhoun. 
frequency of ARD for the GEP and literature models as shown in Fig. 9. Based on Fig. 9, the highest frequency, which is equal to $65 \%$, can be assigned to GEP model around zero error value. In other words, the peak of the normal distribution function in the GEP model is in the nearest neighborhood to zero error, even though the peak of normal distribution is for most from the zero error in Standing (1977) correlation.

The bubble point pressure is the most influencing parameter in PVT analysis which is essential for the reservoir simulation. For any new dataset, the coefficient of the proposed model can easily be tuned. The proposed model can also be integrated into any theoretical model or commercial software for accurate bubble point prediction. To end with, GEP model is efficient and easy-to-utilize for the experts and scientists concerning the accurate determination of PVT properties and consequently the reservoir simulation.

\section{Conclusion}

In the current investigation, one of the most advanced technologies for regression analysis termed as, gene expression programming (GEP), was utilized to create a four-variable representative equation for estimating bubble point pressure. A bulk of 93 measured data points was collected from the petroleum industry. The results of the developed representative equation here were assessed through several analyses such as various error functions and graphical tests. It is understood that the suggested GEP equation is the most precise and trustworthy model with the determination coefficient $\left(\mathrm{R}^{2}\right)$ of 0.96 and the average absolute relative error percent (AARE\%) of $11.41 \%$. The outcomes of the sensitivity analysis reveal that the solution gas-oil ratio is the most influencing parameter affecting the calculation of bubble point pressure. The developed model in this study can be of supreme importance for petroleum engineers dealing with the development of PVT models.

\section{Acknowledgement}

The authors are so grateful to the petroleumdepartment of the national oil company for providing us a valuable database during this modelingstudy.

\section{Conflict of interest}

The authors declare no competing interest.

Open Access This article, published at Ausasia Science and Technology Press on behalf of the Division of Porous Flow, Hubei Province Society of Rock Mechanics and Engineering, is distributed under the terms and conditions of the Creative Commons Attribution (CC BY-NC-ND) license, which permits unrestricted use, distribution, and reproduction in any medium, provided the original work is properly cited.

\section{References}

Ahmadi, M.A., Pournik, M., Shadizadeh, S.R. Toward connectionist model for predicting bubble point pressure of crude oils: Application of artificial intelligence. Petroleum 2015, 1(4): 307-317.

Alakbari, F.S., Elkatatny, S., Baarimah, S.O. Prediction of bubble point pressure using artificial intelligence AI techniques. Paper SPE 184208 Presented at SPE Middle East Artificial Lift Conference and Exhibition, Manama, Kingdom of Bahrain, 30 November-1 December, 2016.

Al-Marhoun, M.A. PVT correlations for middle east crude oils. J. Pet. Technol. 1988, 40(5): 650-666.

Asoodeh, M., Bagheripour, P. Estimation of bubble point pressure from PVT data using a power-law committee with intelligent systems. J. Pet. Sci. Eng. 2012, 90-91: $1-11$.

Bandyopadhyay, P., Sharma, A. Development of a new semi analytical model for prediction of bubble point pressure of crude oils. J. Pet. Sci. Eng. 2011, 78(3-4): 719-731.

Chok, N.S. Pearson's versus spearman's and kendall's correlation coefficients for continuous data. Pittsburgh, University of Pittsburgh, 2010.

Elkatatny, S., Mahmoud, M. Development of a new correlation for bubble point pressure in oil reservoirs using artificial intelligent technique. Arab. J. Sci. Eng. 2018, 43(5): 2491-2500.

Ferreira, C. Gene Expression Programming: Mathematical Modeling by an Artificial Intelligence. New York, USA, Springer, 2006.

Glaso, O. Generalized pressure-volume-temperature correlations. J. Pet. Technol. 1980, 32(5): 785-795.

Ikiensikimama, S.S., Ajienka, J.A. Impact of PVT correlations development on hydrocarbon accounting: The case of the niger delta. J. Pet. Sci. Eng. 2012, 81: 80-85.

Kamari, A., Pournik, M., Rostami, A., et al. Characterizing the $\mathrm{CO}_{2}$-brine interfacial tension (IFT) using robust modeling approaches: A comparative study. J. Mol. Liq. 2017, 246: 32-38.

Khoukhi, A., Albukhitan, S. PVT properties prediction using hybrid genetic-neuro-fuzzy systems. Int. J. Oil Gas Coal Technol. 2010, 4(1): 47-63.

Lasater, J.A. Bubble point pressure correlation. J. Pet. Technol. 1958, 10(5): 65-67.

McCain Jr., W.D., Soto, R.B., Valko, P.P., et al. Correlation of bubblepoint pressures for reservoir oils-A comparative study. Paper SPE 51086 Presented at SPE Eastern Regional Meeting, Pittsburgh, Pennsylvania, 9-11 November, 1998.

Moradi, B., Malekzadeh, E., Amani, M., et al. Bubble point pressure empirical correlation. Paper SPE 132756 Presented at Trinidad and Tobago Energy Resources Conference, Port of Spain, Trinidad, 27-30 June, 2010.

Ostermann, R.D., Owolabi, O.O. Correlations for the reservoir fluid properties of alaskan crudes. Paper SPE 11703 Presented at SPE California Regional Meeting, Ventura, California, 23-25 March, 1983.

Petrosky Jr, G.E., Farshad, F.F. Pressure-volume-temperature correlations for gulf of mexico crude oils. Paper SPE 26644 Presented at SPE Annual Technical Conference and Exhibition, Houston, Texas, 3-6 October, 1993.

Rafiee-Taghanaki, S., Arabloo, M., Chamkalani, A., et al. Implementation of SVM framework to estimate PVT properties of reservoir oil. Fluid Phase Equilib. 2013, 346: 25-32. 
Rostami, A., Hemmati-Sarapardeh, A., Mohammadi, A.H. Estimating n-tetradecane/bitumen mixture viscosity in solvent-assisted oil recovery process using gep and gmdh modeling approaches. Pet. Sci. Technol. 2019, 37(14): 1640-1647.

Shokrollahi, A., Tatar, A., Safari, H. On accurate determination of PVT properties in crude oil systems: Committee machine intelligent system modeling approach. J. Taiwan Inst. Chem. Eng. 2015, 55: 17-26.

Standing, M.B. A pressure-volume-temperature correlation for mixtures of california oils and gases. Paper API-47-275 Presented at Drilling and Production Practice, New York,
USA, 1 January, 1947.

Standing, M.B. Volumetric and Phase Behavior of Oil Field Hydrocarbon Systems. New York, USA, Society of petroleum engineers of AIME, 1977.

Talebi, R., Ghiasi, M.M., Talebi, H., et al. Application of soft computing approaches for modeling saturation pressure of reservoir oils. J. Nat. Gas Sci. Eng. 2014, 20: 8-15.

Vazquez, M., Beggs, H.D. Correlations for fluid physical property prediction. Paper SPE 6719 Presented at SPE Annual Fall Technical Conference and Exhibition, Denver, Colorado, 9-12 October, 1977. 